\title{
Canadian Journal of Remote Sensing
}

Journal canadien de télédétection

\section{A Satellite Assessment of the Urban Heat Island in Morocco}

\section{Najlaa Fathi, Lahouari Bounoua \& Mohamed Messouli}

To cite this article: Najlaa Fathi, Lahouari Bounoua \& Mohamed Messouli (2019): A Satellite Assessment of the Urban Heat Island in Morocco, Canadian Journal of Remote Sensing, DOI: 10.1080/07038992.2019.1601007

To link to this article: https://doi.org/10.1080/07038992.2019.1601007

册 Published online: 25 Apr 2019.

Submit your article to this journal 중

View Crossmark data $₫$ 


\title{
A Satellite Assessment of the Urban Heat Island in Morocco
}

\author{
Najlaa Fathi ${ }^{\mathrm{a}}$, Lahouari Bounoua ${ }^{\mathrm{b}}$, and Mohamed Messouli ${ }^{\mathrm{a}}$

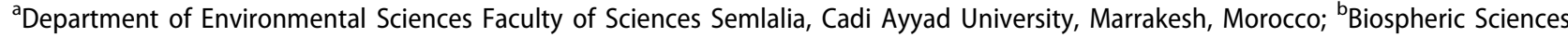 \\ Laboratory, NASA's Goddard Space Flight Center, Greenbelt, MD, USA
}

\begin{abstract}
Urban ecosystems interact with surroundings via land cover changes and their subsequent impact on surface temperature. In emerging countries, large urban agglomerations often form around cities, and only a few studies have evaluated their impact. This study carries out the first ever large-scale assessment of urban heat island (UHI) and reflects on its mitigation in Morocco. The analysis reveals a well-defined UHI in urban areas built within vegetated lands and an urban heat sink (UHS) in urban areas built within arid regions. Both UHI and UHS amplitudes are higher during day than nighttime, emphasizing vegetation physiological activity. This study shows a monotonic increase in UHI amplitude with urban area size. However, unlike previous studies, this analysis shows that, as urban areas built in desert-like environments grow in size, the UHS gradually decreases to ultimately turn into an UHI. On average, cities built within vegetation are warmer than the rural fringe by $1.51{ }^{\circ} \mathrm{C}$ during daytime. This suggests that daytime urban heating may exacerbate the potential climate warming. These results also suggest that adapted trees constitute a natural cooling mechanism and should be part of urban heating mitigation in Morocco.
\end{abstract}

\section{RÉSUMÉ}

L'interaction des écosystèmes urbains avec l'environnement se traduit par des changements dans la couverture terrestre et une modulation de la température de surface qui en résulte. Dans les pays émergents, de grandes agglomérations urbaines se forment autour des villes et seules quelques études ont évalué leur impact. Cette étude réalise la toute première évaluation à grande échelle de l'îlot de chaleur urbain (ICU) et réfléchit à son atténuation au Maroc. L'analyse révèle un ICU bien défini dans les zones urbaines construites dans des zones de végétation et un puit de chaleur urbain (PCU) dans les zones urbaines construites dans des régions arides. Les amplitudes des ICU et PCU sont plus élevées le jour que la nuit, mettant l'accent sur l'activité physiologique de la végétation. Nous montrons une augmentation monotone de I'amplitude ICU avec la taille de la zone urbaine. Cependant, contrairement aux études précédentes, notre analyse montre que, lorsque les zones urbaines construites dans des environnements de type désertique deviennent de plus en plus grandes, le PCU diminue progressivement pour devenir finalement un ICU. En moyenne, les villes construites dans la végétation sont plus chaudes que la périphérie rurale de $1,51^{\circ} \mathrm{C}$ pendant la journée. Cela suggère que la chaleur diurne urbaine pourrait exacerber le réchauffement climatique potentiel. Nos résultats suggèrent également que les arbres adaptés constituent un mécanisme de refroidissement naturel et devraient faire partie de la lutte contre le réchauffement urbain au Maroc.

\section{ARTICLE HISTORY}

Received 10 January 2019

Accepted 26 March 2019

\section{Introduction}

Urbanization is a process whereby populations move from rural to urban areas, forcing them to grow. Urbanization is one of the long lasting forms of land transformation, and presents seemingly conflicting attributes as it occupies a relatively small area but has large socio-ecological consequences with important feedback to ecosystems and climate (e.g., Bounoua et al. 2015a and references therein).
Among the most important impacts of urbanization on surface climate are higher surface temperatures and more frequent heat waves (Chestnut et al. 1998). Urban areas are not all built the same way, nor are they built with the same material. In most urban areas, the material used in buildings and pavement construction is darker than its surroundings. Consequently, it absorbs more energy and causes the urban surfaces and the air immediately around them 
to warm faster than their surrounding vegetated areas. This contrast in temperature creates, thus, the socalled urban heat island (UHI) (e.g., Oke 1982; Quattrochi et al. 2007; Imhoff et al. 2010; Zhang et al. 2010; Zhang et al. 2012; Bounoua et al. 2017). The urban heat island (UHI) is a response to land transformation and is being the center of interest across science disciplines as it affects human activities, health, ecosystem function, and potentially climate. The UHI has several causes, but is essentially related to a reduction in latent, at the expense of sensible, heating in urban areas where building materials with high thermal inertia (Oke 1982; Owen et al. 1998; Imhoff et al. 2010; Bounoua et al. 2015b) has replaced vegetation.

The UHI is defined as the temperature difference between the urban and rural zones. When this difference is positive it is referred to as an UHI; however, when the difference is negative it is referred to as an urban heat sink (UHS), indicating that the urban core is colder than its surroundings (Li et al. 2011; Imhoff et al. 2010; Bounoua et al. 2015b).

The UHI can be studied using either air temperature or surface temperature (Grimmond and Oke 2002; Shepherd and Burian 2003; Imhoff et al. 2010) using data from meteorological stations (e.g., Zhang et al. 2014) or from remote sensing (e.g., Al-Hamdan et al. 2016; Lachir et al. 2016). It has been found that the air temperature UHI is stronger during the night than during the day (Oke 1973; Souch and Grimmond 2006) compared with UHI defined using surface temperature, which is more intense during the daytime (Imhoff et al. 2010; Zhang et al. 2012; Zhao et al. 2014).

Remotely sensed Earth observations are being increasingly used to characterize urban areas in different aspects of urban research (Bounoua et al. 2009; Zhang et al. 2010; Imhoff et al. 2010; Lachir et al. 2016; Al-Hamdan et al. 2016; Bounoua et al. 2015a, 2018a, 2018b) and different remote sensing products have been used to assess the land surface temperature (LST). For example, Chow et al. (1994) and Streutker (2002) used data from the advanced very high resolution radiometer (AVHRR), while Kato and Yamaguchi (2005) and $\mathrm{Lu}$ and Weng (2006) used the Advanced Space borne Thermal Emission and Reflection Radiometer (ASTER) onboard of Terra. On the other hand, Weng (2009) used Landsat Thematic Mapper (TM) - Enhanced Thematic Mapper plus $(\mathrm{ETM}+)$, while Frey et al. (2012) used data from the Moderate Resolution Imaging Spectroradiometer (MODIS). More recently, Imhoff et al. (2010) and
Zhang et al. (2010) used remotely sensed impervious surface area (ISA) as an indicator of the extent and intensity of urbanization for UHI analysis at regional and global scales. Previous studies reported that UHI was higher in summer than in winter over different cities (e.g., Zhang et al. 2005). In the US, Imhoff et al. (2010) show that, on yearly average, urban areas are substantially warmer than the non-urban fringe by $2.9^{\circ} \mathrm{C}$ and that a remarkable asymmetry existed between average UHI during summer $\left(4.3^{\circ} \mathrm{C}\right)$ and winter $\left(1.3^{\circ} \mathrm{C}\right)$. On the other hand, Yuan and Bauer's (2006) analysis indicated a strong linear relationship between LST and ISA for all seasons, whereas the relationship between LST and NDVI was much less strong and varied by season. The background local climate contribution to UHI is detailed in Zhao et al. (2014).

In Morocco, a semi-arid country in North Africa, cities have increased rapidly following economic development. For instance, circa 2014 about 59.7\% of the total population lived in cities (UN 2014). This urban growth has directly increased the demand for housing, roads, parks, and business buildings, and often at the expense of suburban or rural vegetated lands. To date, only a few recent studies have assessed the impact of urbanization and evaluated the UHI over 2 urban areas in Morocco, Casablanca (e.g., Azmi et al. 2015; Bahi et al. 2016) and Marrakech (Lachir et al. 2016), and have linked the UHI effect to rapid local urbanization with no indication about UHI spatial distribution nor its national impact. The objective of this study is to combine Landsat and MODIS data to map urbanization and to assess its associated UHI throughout Morocco. This is the first extensive study using satellite data to characterize the UHI over the 24 largest urban areas of Morocco.

\section{Study area}

Morocco is located in North West Africa and extends along the North Atlantic Ocean (Figure 1) over an area of $710,850 \mathrm{~km}^{2}$ (HCP, Haut-Commissariat au Plan Rabat, MAROC 2006). It is administratively subdivided into 12 regions, its population totals 33.8 million inhabitants, of which more than half live in urban areas circa 2014 (RGPH 2015). The administrative capital of Morocco is Rabat and its economic capital and largest urban area is Casablanca. Compared to a census conducted by the High Commission for Planning (HCP) in 2014, Morocco is experiencing a growing urbanization at the expense of rural living. In 2004 , the urbanization rate was $\sim 55 \%$, currently it is 


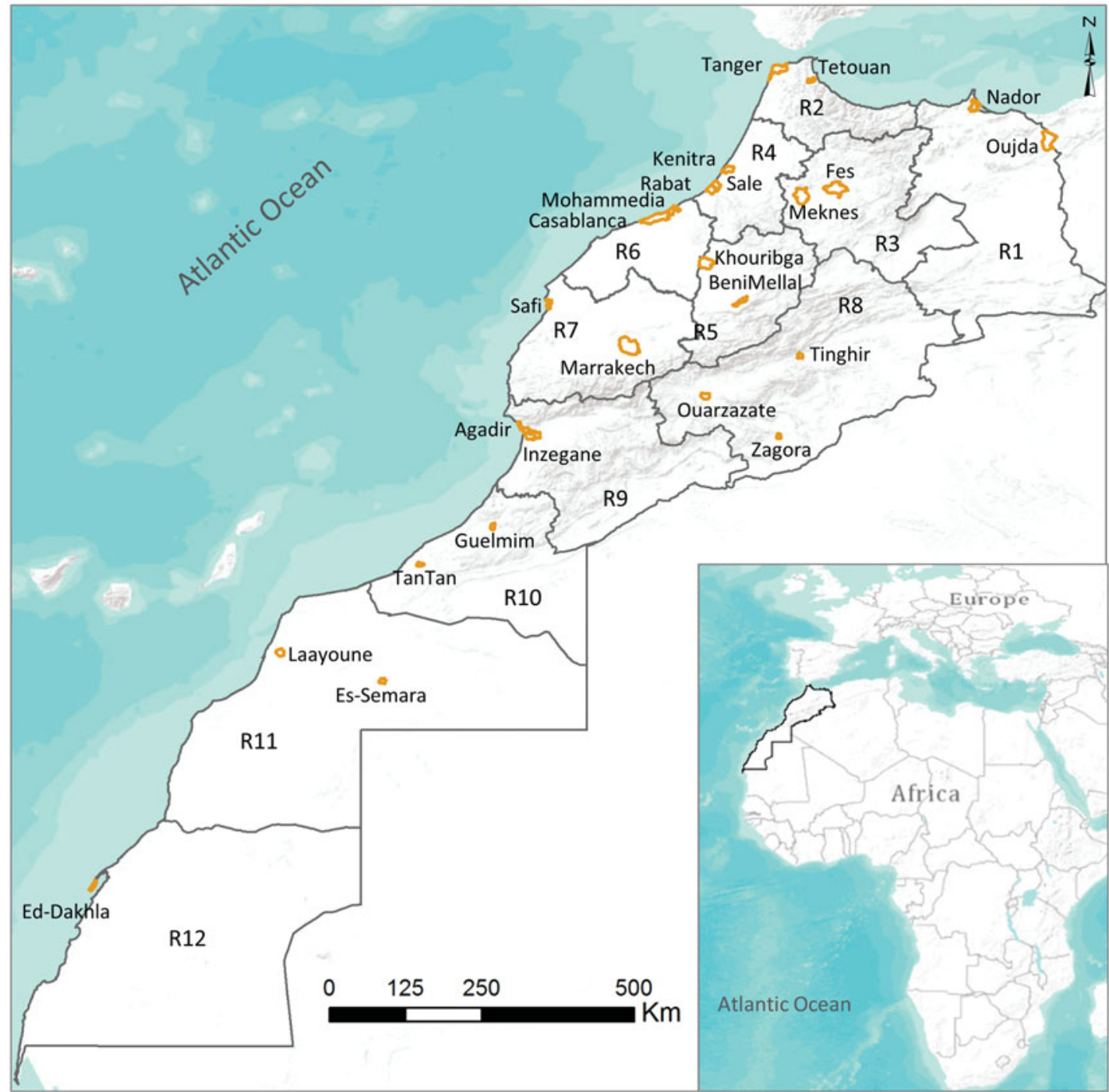

Figure 1. Study region (Morocco) and location of the sampled urban areas.

$\sim 60.2 \%$ (UN-HABITAT 2016). This urban growth has had significant consequences on urban surface temperature.

Morocco's climate varies from temperate along the coasts with mild winters and dry warm summers, to continental in the interior, with colder winters and hot and dry summers. The southern regions are semiarid and turning to arid within the Sahara desert (Library of Congress 2006; MCCP, Morocco's Climate Change Policy 2014).

\section{Materials and methods}

\section{Mapping the urban areas from Landsat}

The study uses 48 Landsat- 8 scenes at $30 \mathrm{~m} \times 30 \mathrm{~m}$ horizontal resolution for the year 2013 from the US Geological Survey (USGS) to cover the study areaMorocco. Landsat data was used to differentiate artificial surfaces-impervious surfaces from natural surfaces. We employed a Geographic Information System (GIS) based on spatial analysis for all pretreatments and a supervised classification to map the land cover over the study region.

Satellite images taken by sensors generally contain atmospheric effects. An atmospheric correction was applied to extract these effects from observations; here we converted Landsat digital numbers to physically measure top of atmosphere reflectance (TOA) and used the dark object subtraction (DOS), a widely used method, to carry out the atmospheric correction (Norjamaki and Tokola 2007). A supervised classification of urban and non-urban areas was then performed. Landsat images were used within the supervised maximum likelihood classifier (ML) based on Bayes' classification and in which a pixel is assigned to a class according to its probability of belonging to a particular class (Lillesand et al. 2004). 
Table 1. Confusion matrix of the scene that contains the Nador urban area.

\begin{tabular}{lrrrrr}
\hline \multicolumn{6}{l}{ Ground Truth (Percent) } \\
\hline Class & \multicolumn{1}{l}{ Soil } & Vegetation & Water & Urban & Total \\
\hline Unclassified & 0.00 & 0.00 & 0.00 & 0.00 & 0.00 \\
Soil & 97.17 & 0.00 & 0.87 & 5.11 & 47.50 \\
Vegetation & 0.67 & 100.00 & 0.17 & 0.00 & 24.25 \\
Water & 2.07 & 0.00 & 98.96 & 0.00 & 19.96 \\
Urban & 0.09 & 0.00 & 0.00 & 94.89 & 8.29 \\
Total & 100.00 & 100.00 & 100.00 & 100.00 & 100.00 \\
\hline
\end{tabular}

Note. Overall Accuracy $=98 \%$.

Before launching a classification, 4 classes: urban, vegetation, water, and bare soil, were defined in order to avoid confusion between classes that have similar reflectance and to distinguish the transition between the built and the natural environment. For that we created 2 sets of training regions (region of interest, ROI) for the 4 classes by digitizing polygons based on high resolution images from Google Earth and on site observation where available, 1 set was used for the classification and the other set was used for the validation. In total, 300-400 samples, depending on the composition of scenes, spread across the region and classes, were used. The confusion matrix and visual analysis were used to assess the classification's quality. Overall, the classification presents an accuracy between $80 \%$ and $98 \%$ over the 48 scenes. An example of the confusion matrix for the region of Nador is presented in Table 1, while Figure 2 shows an example of the classification and emphasizes the impervious surface area (ISA) for 3 different urban areas.

For this paper, we selected the urban class and produced an ISA product at $1 \mathrm{~km} \times 1 \mathrm{~km}$ resolution expressed in percent. To do that, we aggregate the urban class from $30 \mathrm{~m} \times 30 \mathrm{~m}$ resolution within a $1 \mathrm{~km} \times 1 \mathrm{~km}$ and express the fraction of urban area in percent of the $1 \mathrm{~km} \times 1 \mathrm{~km}$ grid. Figure $3 \mathrm{~A}$ shows an example of the aggregation for the urban area of Tangier. We then stratify each individual urban area into 3 zones based on ISA density and defined starting from the core of the urban area and going outward, the urban core with pixels having more than $25 \%$ ISA (ISA $\geq 25 \%$ ), the suburban zone containing pixels with ISA between $25 \%$ and $5 \%$ (25\%> ISA $\geq 5 \%)$ and the rural or non-urban zone with pixels having less than $5 \%$ ISA (ISA $<5 \%$ ) and located within the administrative boundaries of each urban area (Figure 3A). The stratification follows that of Imhoff et al. (2010) established for US cities but differs from it in term of thresholds of ISA delimiting the different zones. In our study region, the urban areas are formed of disorganized conglomerate of impervious surface with frankly detectable density contrast between the urban core and the suburbs, but no clear separation exists between the suburbs and rural zones. Furthermore, while Imhoff et al. (2010) stratification included 5 separate zones, the one presented here is a simplified 3-zones version adapted to the size of the urban areas in our study region.

We applied this stratification throughout the study region and calculated the urban core size for all urban areas, which totaled 140 . In order to reduce the number of urban areas, we have selected 2 per region based on the largest urban core size in each of the 12 administrative regions (Figure 1). In Eddakhla-Oued Eddahab region (R12), the only urban area detected with Landsat was that of Eddakhla; however, it did not have viable land surface temperature (LST) data available for the study of UHI. For this reason, we augmented the number of urban areas to 3 for the regions of Rabat-Sale-Kénitra (R4) from northern Morocco and the region of the Draa-Tafilalet (R8) in southern Morocco for a total of 24 urban areas fully characterized by Landsat and MODIS data. The selected urban areas are listed in Table 2.

For each urban area defined in Table 2, we analyzed the urban heat island (UHI), the urban heat sink (UHS) during both growing and non-growing seasons and during day and nighttime. The growing season was determined using the normalized difference vegetation index (NDVI). Further grouping is performed during the analysis based on urban cores presenting a UHI versus those having a UHS, another comparison based on urban core size was also set to compare urban cores with size less than $25 \mathrm{~km}^{2}$, to those with core size between $25 \mathrm{~km}^{2}-45 \mathrm{~km}^{2}$ and those with core size more than $45 \mathrm{~km}^{2}$. A second analysis included urban cores with a size less than $5 \mathrm{~km}^{2}$, between $5 \mathrm{~km}^{2}-15 \mathrm{~km}^{2}$ to those having more than $15 \mathrm{~km}^{2}$ in size. This size-based analysis is inspired by the study of Zhang et al. (2010). However, because in our study region urban areas are smaller compared to those in the US, we grouped them based on scales commensurate to their sizes.

\section{Normalized difference vegetation index (NDVI)}

To describe the variation of the vegetation density over each zone of the selected urban areas, we used the 16-day, $500 \mathrm{~m} \times 500 \mathrm{~m}$ (MOD13A1) composite time series of MODIS NDVI from version 6 covering the entire year of 2013 (Huete et al. 1994, 1997). The NDVI was reprojected from its original sinusoidal 

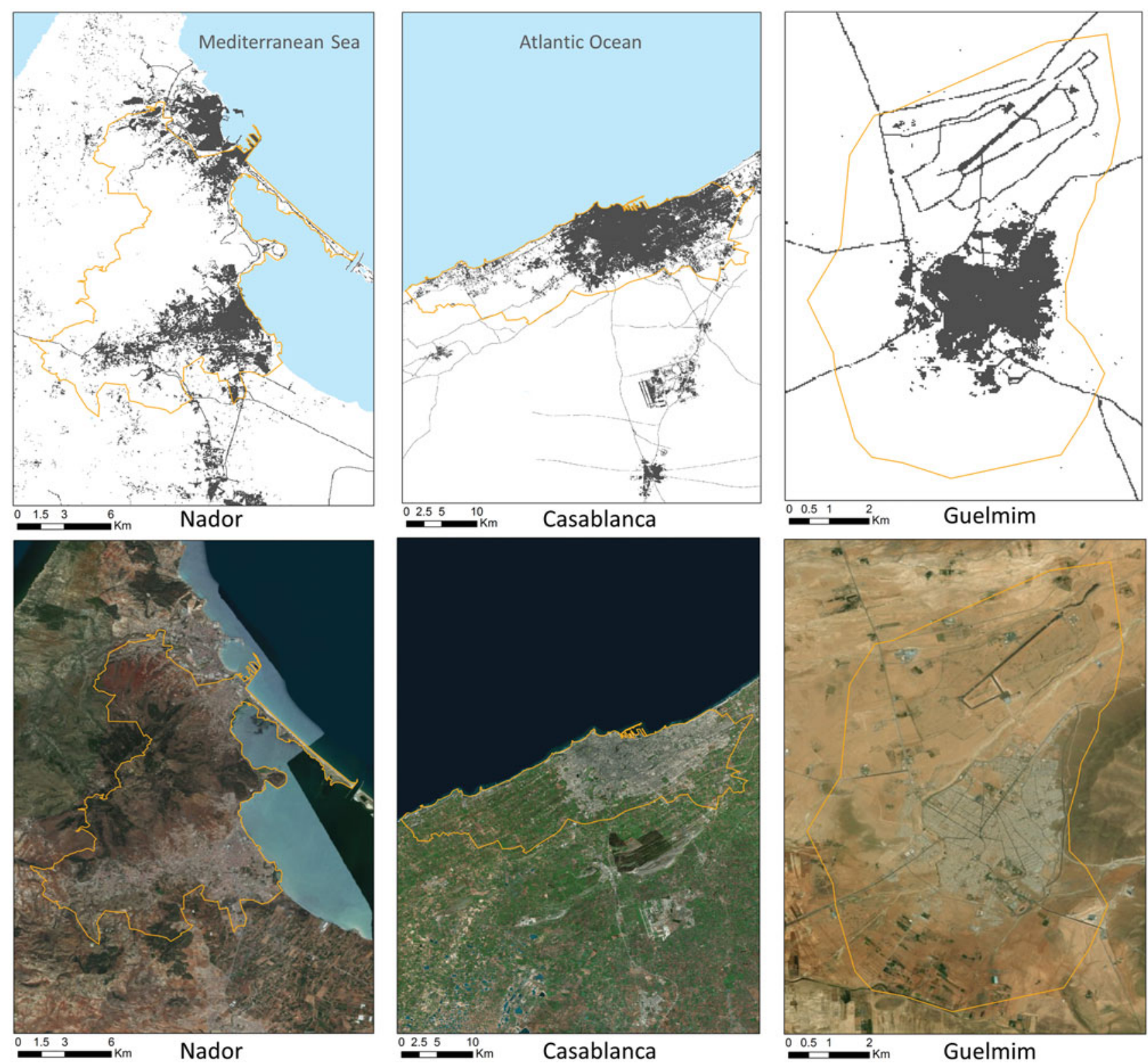

Figure 2. Upper panels: example of the classification outcome for the 3 named urban areas. Darkened regions represent urban areas and white regions represent a mix of vegetation and bare soil. Orange contours represent the administrative limits of the designated urban areas. Lower panels are the same size Google Earth (GE) images showing, in grey color, the urban areas within the contour limiting the designated urban areas. GE images are provided for visual comparison only.

projection to UTM WG84 using the MODIS Reprojection Tool (Dwyer and Schmidt 2006) and coregistered to conform to aggregated imagery. A data quality analysis was performed to remove low quality NDVI values. Quality Assurance maps (QA) for MODIS products were developed (Roy et al. 2002). These maps are presented as data layers embedded in MODIS products. For this study, the assessment of the data quality was carried out using the TiSeG tool "Time-series generator" (Colditz et al. 2008). According to user-defined settings, the tool visualizes the spatial and temporal data availability by generating 2 indices, the number of invalid pixels and the maximum gap length. This tool allows users to decode the quality layer information (QA), define the desired quality criteria, and filter the data according to these criteria. The quality settings can be user-modified spatially and temporally to account for regional and seasonal variations of data quality. The user can then visualize the filtered valid data (result of the quality analysis), record the data where the invalid pixels are either masked or reconstructed by spatial or temporal interpolation.

We finally used the $1 \mathrm{~km}$ raster grid and converted the pixels to polygons to obtain shape file covering Morocco. Using this gap-filled NDVI product and the 
(A)
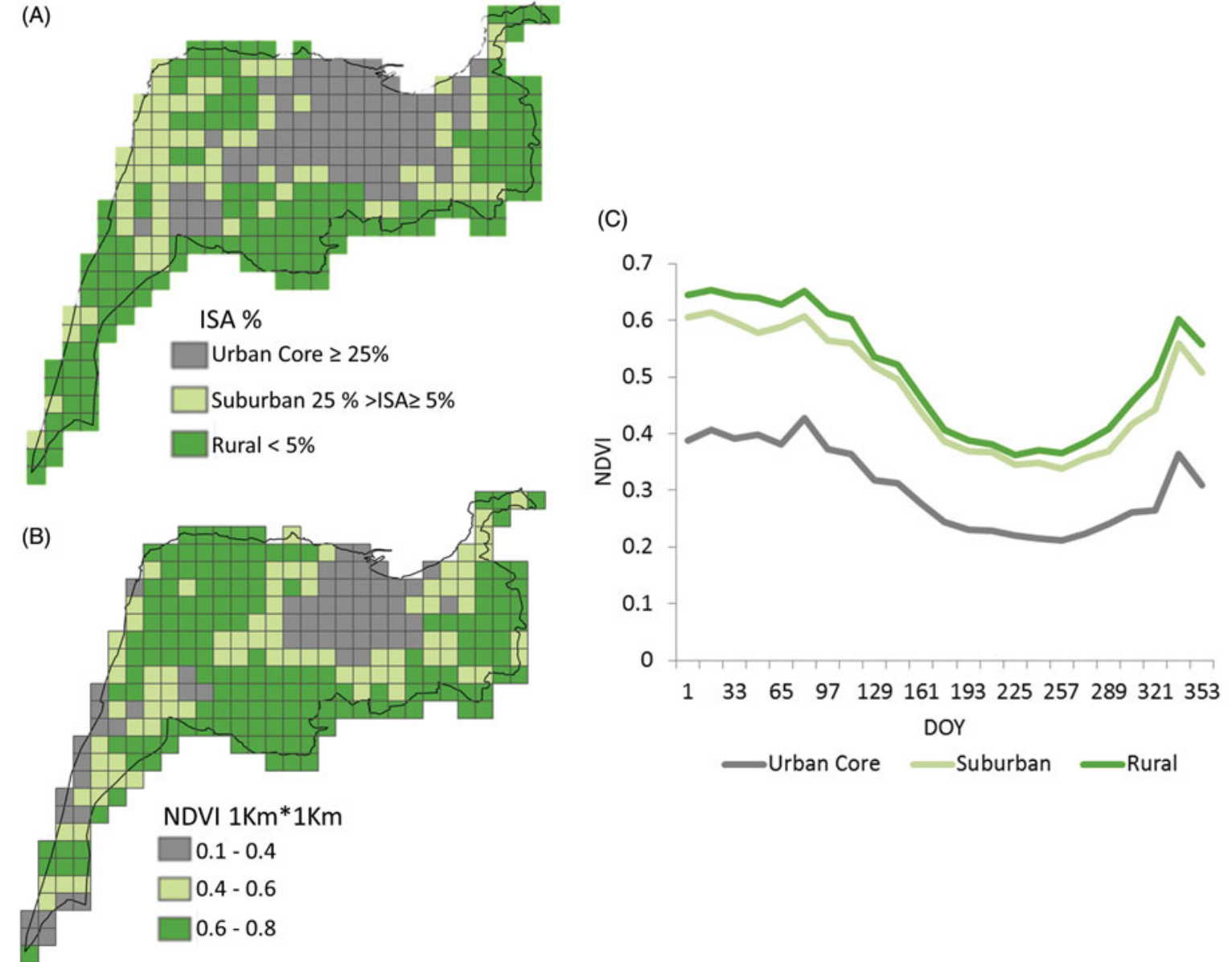

Figure 3. Urban area of Tangier, (A) Impervious surface area (\%) obtained by aggregation to $1 \mathrm{~km}$ pixel; (B) Mean NDVI for Period 1 at $1 \mathrm{~km} \times 1 \mathrm{~km}$ pixel; and (C) Time series of mean NDVI for each of the 3 zones.

Table 2. Selected urban areas for each region.

\begin{tabular}{llll}
\hline Regions & Selected Urban Areas & \multicolumn{1}{c}{ Regions } & Selected Urban Areas \\
\hline Oriental (R1) & Nador & Marrakech-Safi (R7) & Safi \\
& Oujda & Marrakech \\
Tangier-Tetouan-Al Hoceima (R2) & $\begin{array}{l}\text { Tangier } \\
\text { Tetouan }\end{array}$ & Draa-Tafilalet (R8) & $\begin{array}{l}\text { Zagora } \\
\text { Zinghir }\end{array}$ \\
& Meknes & & Agadir \\
Fes-Meknes (R3) & Fes & Souss-Massa (R9) & Inzegane \\
& Sale & Guelmim-Oued Noun (R10) & $\begin{array}{l}\text { Tantan } \\
\text { Rabat-Sale-Kenitra (R4) }\end{array}$ \\
& $\begin{array}{l}\text { Kenitra } \\
\text { Rabat }\end{array}$ & Guelmim \\
Beni Mellal-Khenifra (R5) & Beni-Mellal Khouribga & Laayoune-Sakia El Hamra (R11) & Essmara \\
& Caayoune \\
Grand Casablanca-Settat (R6) & Casablanca Mohammedia & Eddakhla-Oued Eddahab (R12) & Eddakhla \\
\hline
\end{tabular}

$1 \mathrm{~km}$ shape file, we computed the mean NDVI within the $1 \mathrm{~km} \times 1 \mathrm{~km}$ pixel for the 2316 -day MODIS composite periods of the year. Figure $3 \mathrm{C}$ shows an example of the averaged NDVI time-series for the Tangier urban area. This filtered NDVI data is used to define the growing season (GS) and non-growing season (NGS) for each urban area. The growing season is limited between its onset, defined as the first period where the NDVI starts to increase, and the end of the senescence phase where the NDVI reaches a threshold density. An example of determination of GS and NGS for the urban region of FES is presented in Figure 4.

\section{Land surface temperature (LST)}

We use MODIS-Aqua version 05 8-day composite land surface temperature (MYD11A2) at $1 \mathrm{~km} \times 1 \mathrm{~km}$ 


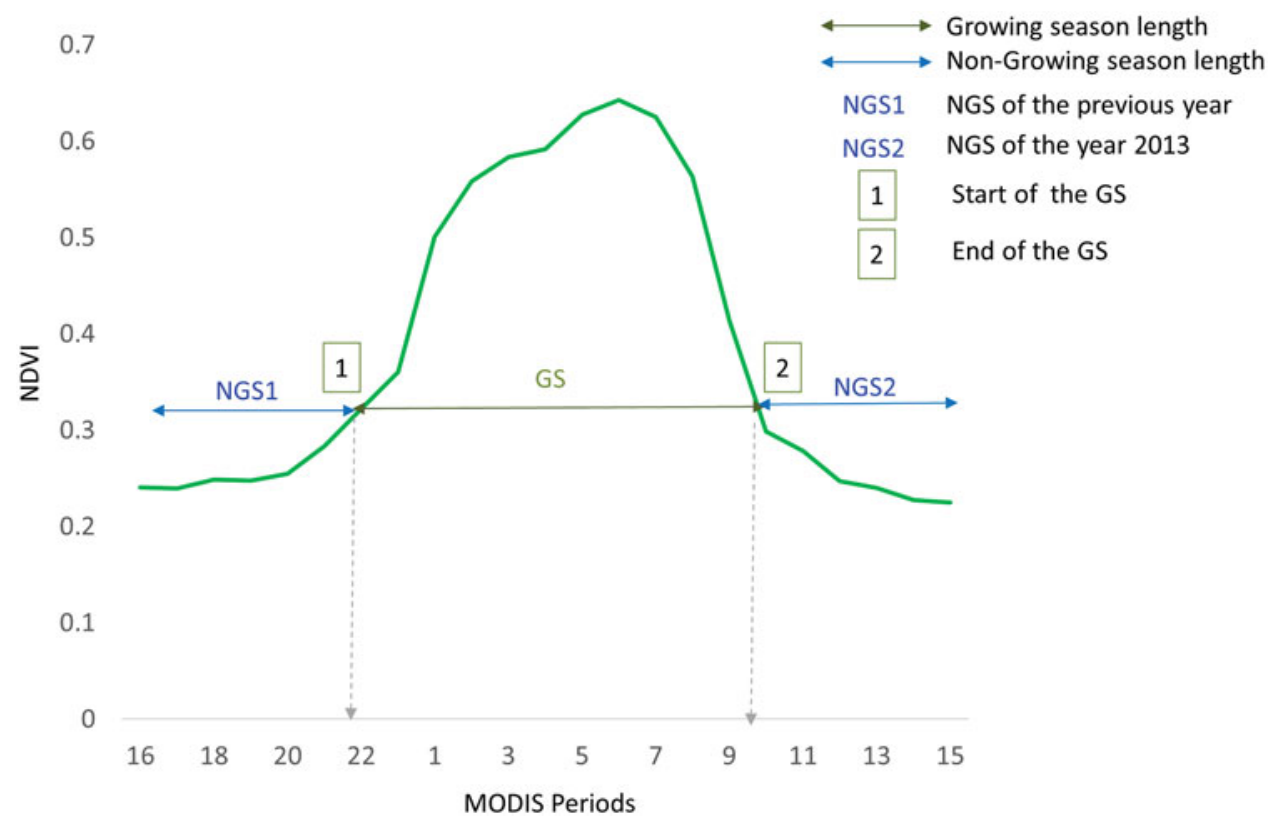

Figure 4. NDVI values for the urban area of Fes composited every 16 days for the year 2013. The figure is for illustration purpose and shows the determination of the growing season (GS). The total non-growing season combines the 2 NGS periods shown on each side of the GS.

horizontal resolution. The data was filtered using pixel-level quality assurance information to generate high quality surface temperature values. We use the same MODIS-algorithm (TiSeG) and same methodology to fill gaps in LST time series. MODIS LST data was compared to in-situ measurements and was found to be accurate to better than $1 \mathrm{~K}$ in most clear sky cases (Wang et al. 2008).

The LST was used to characterize the horizontal temperature gradient across the different zones of the urban areas. Therefore, the urban area temperatures were obtained over the respective zones at daytime 1:30 pm and nighttime 1:30 am and the UHI was computed as the temperature difference between the urban core and the rural zone for each of the selected urban area. For some urban areas, for which we could not estimate the GS, the UHI was estimated for the summer (June-August) and winter (November-January) seasons.

\section{Results and discussion}

\section{The urban heat island: regional scale}

Using Impervious Surface Area (ISA) data, a spatial stratification defining 3 ISA zones is applied for each of the 24 urban areas. To assess the amplitude and phase of the UHI over the selected urban areas, we calculated the spatial average temperature differences between the urban core and the rural zone for all urban areas during the growing season (GS) and outside of the growing season (NGS) at $1: 30 \mathrm{pm}$ (daytime) and 1:30 am (nighttime). The GS and NGS were determined using local vegetation phenology based on the 16-day composite NDVI seasonal cycle. In urban areas characterized by an insignificantly small value of NDVI, or those which did not have a well-defined seasonal cycle, we have calculated the UHI during summer time (June-August) and wintertime (December-February) at the same satellite overpass. For all regions, we were able to identify the GS and NGS seasons except for the urban areas of Zagora and Tinghir in region R8, Tantan in region 10, and Essmara and Laayoune in region 11.

As expected and in line with previous research's results obtained over North Africa (e.g., Bounoua et al. 2009; Lachir et al. 2016), in all regions the greatest temperature differences are noted during the growing season daytime. However, the geographic location of the urban areas (e.g., high vs. low altitude) and their rural surroundings imposed some inter-urban variations and contrasts between the region's UHI diurnal cycles. For all the 24 urban areas studied using the vegetation phenology, 16 presented an UHI and 3 presented an UHS. 5 urban areas had no significant growing season.

The analysis of the UHI reveals 2 distinct categories of urban areas: a category with positive UHI for urban areas built within vegetated regions and a category with negative UHI or Urban Heat Sink (UHS) for those urban areas built within desert-like regions. The first category did not present a large variance in term of inter-regions GS-UHI amplitude. For example, the 
Table 3. Urban areas growing season (GS) daytime and nighttime UHI amplitude in each of the regions. For Zagora, Tinghir, TanTan, Es Semara, and Laayoune, the UHI was computed during summer and winter (see text for details).

\begin{tabular}{|c|c|c|c|c|c|c|c|}
\hline Region & Cities & GS Day & GS Night & Region & Cities & GS Day & GS Night \\
\hline \multirow[t]{2}{*}{ Region 1} & Nador & 1.51 & 1.1 & Region 7 & Safi & 1.53 & 1.27 \\
\hline & Oujda & 1.31 & 1.12 & & Marrakech & 0.77 & 0.75 \\
\hline \multirow[t]{3}{*}{ Region 2} & Tangier & 1.87 & 1.01 & Region 8 & Ouarzazate & -0.33 & 0.42 \\
\hline & Tetouan & 1.55 & 0.91 & & Zagora & -1.65 & -0.35 \\
\hline & & & & & Tinghir & -2.07 & -1 \\
\hline \multirow[t]{2}{*}{ Region 3} & Meknes & 1.57 & 1.05 & Region 9 & Agadir & 1.13 & 0.79 \\
\hline & Fes & 1.85 & 1.5 & & Inezgane & -0.32 & 0.54 \\
\hline \multirow[t]{3}{*}{ Region 4} & Sale & 1.71 & 1.4 & Region 10 & Guelmim & -0.78 & -0.07 \\
\hline & Rabat & 2.07 & 1.69 & & TanTan & 0.25 & 0.53 \\
\hline & Kenitra & 1.3 & 0.71 & & & & \\
\hline \multirow[t]{2}{*}{ Region 5} & Beni Mellal & 0.95 & 0.46 & Region 11 & EsSemara & 0.04 & -0.11 \\
\hline & Khouribga & 1.73 & 0.88 & & Laayoune & 0.48 & 0.44 \\
\hline \multirow[t]{2}{*}{ Region 6} & Mohammedia & 1.36 & 1.19 & Region 12 & Eddakhla & NA & NA \\
\hline & Casablanca & 1.94 & 2.1 & & & & \\
\hline
\end{tabular}

spatially averaged UHI for the 16 urban areas is $1.51 \pm 0.36^{\circ} \mathrm{C}$. On the other hand, the small number of urban areas presenting an UHS led to a much larger standard deviation around the mean $-0.48 \pm 0.26^{\circ} \mathrm{C}$. To present a perspective on the range of the UHI/UHS over all the regions, we show all the selected urban areas' GS day- and nighttime UHI amplitude in each of the 12 regions (Table 3). Among all urban areas of Morocco, Rabat the capital city has the highest daytime UHI amplitude of $2.07^{\circ} \mathrm{C}$ and $1.69^{\circ} \mathrm{C}$ at night and this is related to its impervious area density, which represents $64.41 \%$ of the urban core, and its surrounding vegetation composed of trees and lawns. On the other hand, Marrakech presents the smallest daytime UHI of $0.77^{\circ} \mathrm{C}$.

For some urban areas, the daytime and nighttime mean UHI had statistically significant different amplitudes at the $95 \%$ confidence level. For example, the daytime $\mathrm{UHI}$ is $1.87^{\circ} \mathrm{C}$ and the nighttime is $1.01{ }^{\circ} \mathrm{C}$ in Tangier, a large urban area located in the Mediterranean coastal region (R2), whereas in Marrakech, an urban area located in the semi-arid interior region (R7), the daytime and nighttime UHI amplitude of $0.77^{\circ} \mathrm{C}$ and $0.75^{\circ} \mathrm{C}$, respectively, show a non-statistically significant difference with $p$-value $=$ 0.08 . The diurnal variation of the UHI amplitude is a signature of the role of vegetation in the modulation of surface temperature between urban core and the surrounding rural zones. During daytime when photosynthesis is active in the rural zone, it generates transpiration cooling which strongly contrasts with the urban core high temperature to produce a large daytime UHI amplitude. At nighttime, the vegetation is dormant, therefore, not cooling the air while the urban core cools faster; leading to a reduction of the UHI. This contrast in the diurnal UHI amplitude is not evident in Marrakech, an urban core surrounded by sparse vegetation.
For the urban areas in arid environment like Ouarzazate, Inezgane, and Guelmim, we found that the UHI is transformed into an urban heat sink (UHS). There, the cooling associated with the transpiration from imported exotic trees and irrigated lawns in the urban core makes it cooler than the surrounding desert temperatures.

Because of the similitude in the urban areas' UHI patterns between regions, we elect to show the urban area of Tangier as a representative of the TangierTetouan-Al Hoceima region in the northern Mediterranean part of the country for the UHI, and the urban region of Guelmim as representative of the southern region of Guelmim-Oued Noun for the UHS. The graphical representations of the UHI computed for the 2 urban areas during the growing season day and nighttime is shown in Figure 5. While the urban area of Tangier shows a fully developed daytime and nighttime UHI, a clear reversal in the sign of the urban core minus rural zone surface temperature is observed in Guelmim, revealing a well-defined UHS with an amplitude of $0.78^{\circ} \mathrm{C}$ during the day and an insignificant trend at night. Guelmim is the capital city of the Guelmim-Oued Noun region and a gateway to the desert. Its climate, relatively mild and wet during the growing season (November to March) allows for several varieties of trees and shrubs, including the iconic palm-trees. This vegetation is maintained through resource augmentation (fertilization and irrigation) and plays an important role in reducing the daytime surface temperature in the urban core as compared to the surrounding rural zone, maintaining thus a relatively larger UHS.

\section{UHI and vegetation: urban area scale}

We selected the urban area of Tangier to illustrate the relationship between the LST and the vegetation 


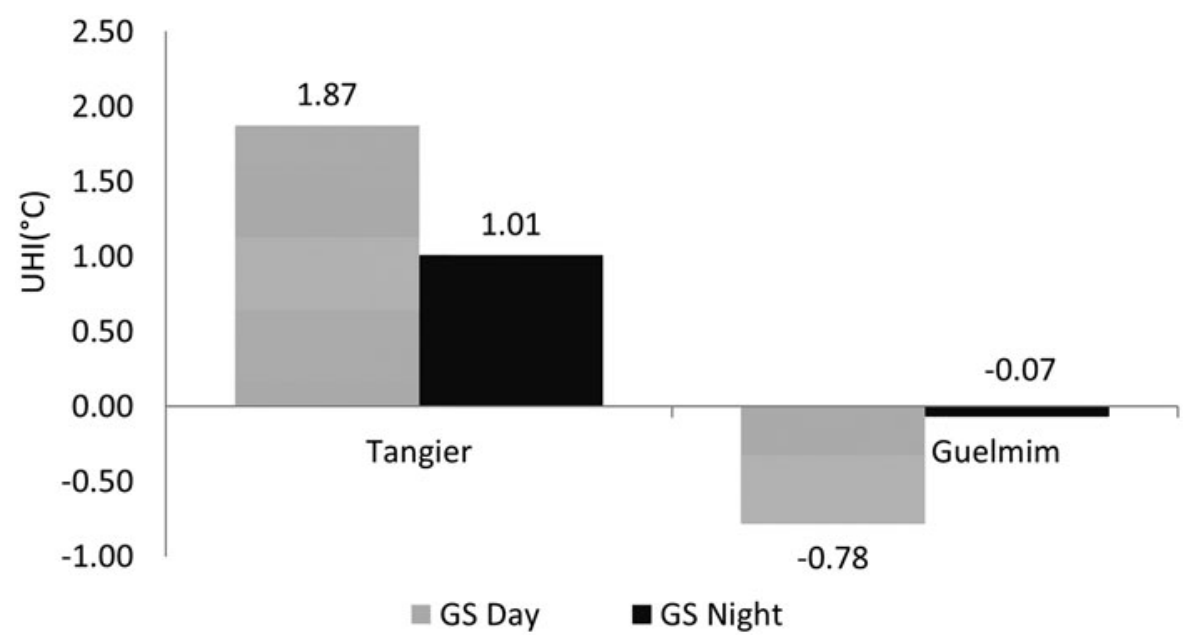

Figure 5. Growing season daytime and nighttime urban heat island amplitude for the urban areas of Tangier and Guelmim.

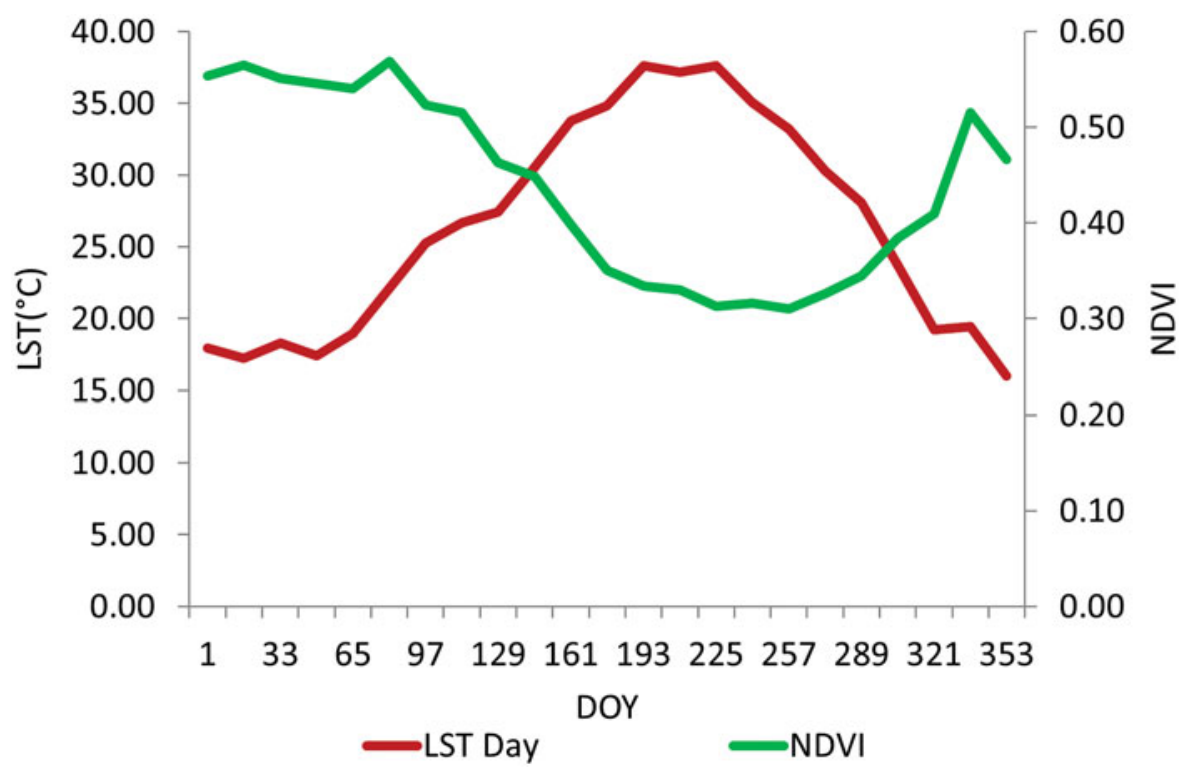

Figure 6. Seasonal variation of spatial average daytime LST and NDVI for the Tangier urban area.

activity as represented by the density of its NDVI. The effect of vegetation in modulating land surface temperature is documented in Bounoua et al. (2015b), who showed that the daytime mean temperature difference between impervious and vegetated lands is correlated to daytime vegetation transpiration and suggested that the amount and choice of tree species in urban areas plays an important role in modulating surface temperature and represents a natural cooling mechanism to reduce the urban heat generated by the build-up. Analysis of LST and NDVI in the urban area of Tangier reflects this dynamic at the annual cycle. Indeed a strong inverse relationship exists between the daytime LST and the NDVI composited over the same 16-days period (Figure 6). The daytime surface temperature is highest during summer months when vegetation density is low and reaches its minimum during the growing season when the vegetation reaches its maximum density and reduces the surface temperature through evaporation.

For the region of Tangier, the monthly average LST reaches about $37.4{ }^{\circ} \mathrm{C}$ during the month of July, while the average NDVI reaches the smallest value (0.33). This phase opposition between the LST and the NDVI indicates that a large part of the contrast in temperature making the Surface UHI is generated by vegetation surrounding the urban areas. The summer (JJA) mean diurnal temperature range (dtr), obtained as a difference between summer daytime and nighttime temperatures, is $\sim 5.45^{\circ} \mathrm{C}$ (Table 4 ), this represents a lower value compared to that of the winter (DJF) dtr of $\sim 10.62{ }^{\circ} \mathrm{C}$ and is characteristic of coastal humid urban areas where nighttime cooling is slowed by high air relative humidity. 
The analysis is carried further to include the variation in LST during the summer and winter, both during daytime and nighttime (Figures 7A and 7B). Since this region's growing season (GS) extends into late spring-early summer, its mean dtr of $5.35^{\circ} \mathrm{C}$ (Figure $7 \mathrm{C}$ ) is similar to that found during summer months. To isolate the role of vegetation on the region's dtr we also calculated the mean surface temperatures during the non-growing season's (NGS) daytime and nighttime (Figure 7D). During the NGS the vegetation is not active; thus most of the energy received from the sun during the daytime is absorbed by the soil and because there is no, or little, soil moisture a large part of the energy is restored as sensible heat and used to increase surface temperature (Bounoua et al. 2015b; Lachir et al. 2016). The fast response of surface temperature to energy input leads to the daytime stored energy to quickly restore to the air at night in the form of long wave radiation, resulting in the highest $\mathrm{dtr}$ of the season, $\sim 13.96^{\circ} \mathrm{C}$.

From this analysis, one can suggest that the cooling effect of vegetation on surface temperature may be represented by the difference between the GS and

Table 4. Monthly mean day and night time LST and NDVI for Tangier.

\begin{tabular}{lccc}
\hline Months & LST Day $\left({ }^{\circ} \mathrm{C}\right)$ & LST Night $\left({ }^{\circ} \mathrm{C}\right)$ & NDVI (Unit less) \\
\hline January & 17.60 & 7.71 & 0.55 \\
February & 17.85 & 6.51 & 0.54 \\
March & 20.55 & 8.79 & 0.55 \\
April & 25.98 & 22.50 & 0.52 \\
May & 29.01 & 28.34 & 0.45 \\
June & 34.31 & 34.17 & 0.36 \\
July & 37.40 & 27.15 & 0.33 \\
August & 36.35 & 20.13 & 0.31 \\
September & 31.77 & 17.34 & 0.32 \\
October & 28.10 & 14.46 & 0.34 \\
November & 21.45 & 10.05 & 0.40 \\
December & 17.72 & 8.36 & 0.44 \\
\hline
\end{tabular}

NGS daytime average values which for the urban area of Tangier is a cooling of about $-4.06^{\circ} \mathrm{C}$.

To further explore the seasonal variation of the UHI amplitude in this region, we carry out the analysis using the stratification developed over the 3 zones. The UHI is computed as a difference in temperature between the urban core and the rural zone and is compared to the NDVI difference over the same zones. The analysis is carried out monthly and following the vegetation seasonal cycle for both day and nighttime.

The seasonal variation of the UHI as well as the NDVI is shown in Figure 8. The UHI is positive for most of the year, implying a higher temperature in the urban core than the surrounding. UHI with a maximum amplitude of $3.1^{\circ} \mathrm{C}$ during the month of June (DOY 129). During winter days, however, the urban core becomes cooler than the rural zone forming thus an UHS. This reversal in the sign of the UHI is due in large part to 2 physical phenomena-albedo and evaporation. During the winter, in addition to high albedo in the urban core, the soils are exposed and precipitation water evaporates at potential rates, thus exacerbating the cooling compared to rural zones, in which transpiration is limited by low temperatures, thus shunting most of the absorbed energy into sensible heating. These results are consistent with previous urban studies over other arid and semi-arid regions, which showed that urban areas exhibit a relatively weak UHI (Bounoua et al. 2009), and sometimes even a heat sink when evaporation is important (Shepherd 2006). On the other hand, the seasonal variation of NDVI is negative year-around, implying that the rural zone is always greener than the urban core. However, within this paradigm the increase in vegetation density in the rural zone during the growing season results in largest NDVI differences and

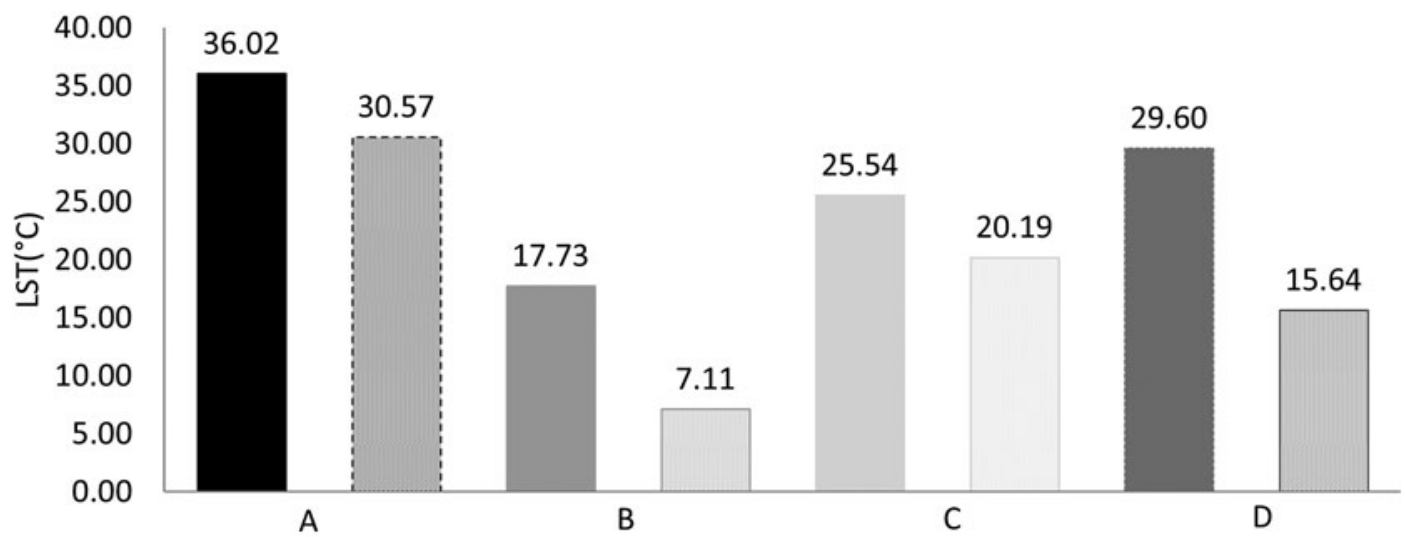

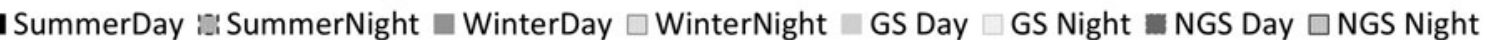

Figure 7. LST for summer, winter, GS, and NGS day- and nighttime for the Tangier urban area. 


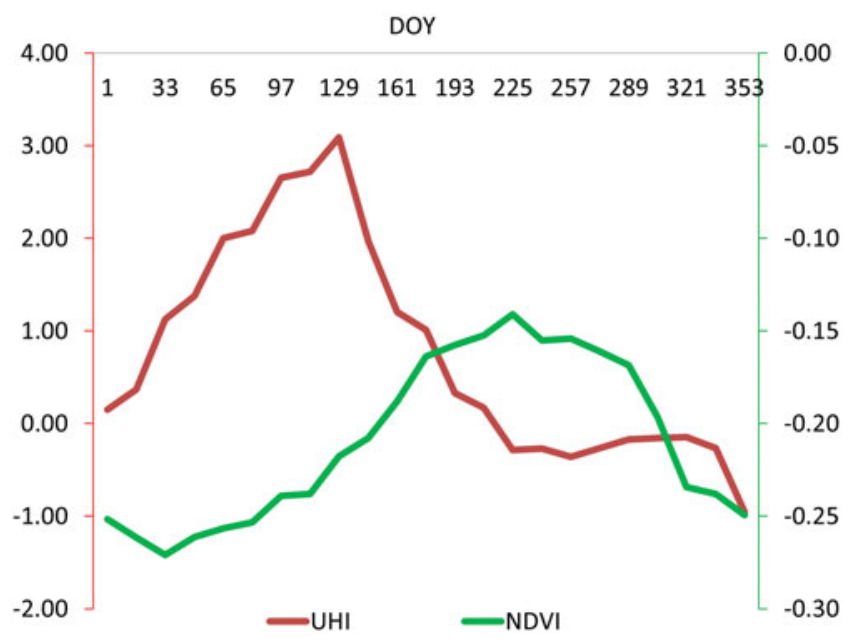

Figure 8. Relationship between NDVI difference (green) between the urban core and the rural zone on the right-axis (dimensionless) and UHI ( $\left.{ }^{\circ} \mathrm{C}\right)$ (red) left-axis for the Tangier urban area.

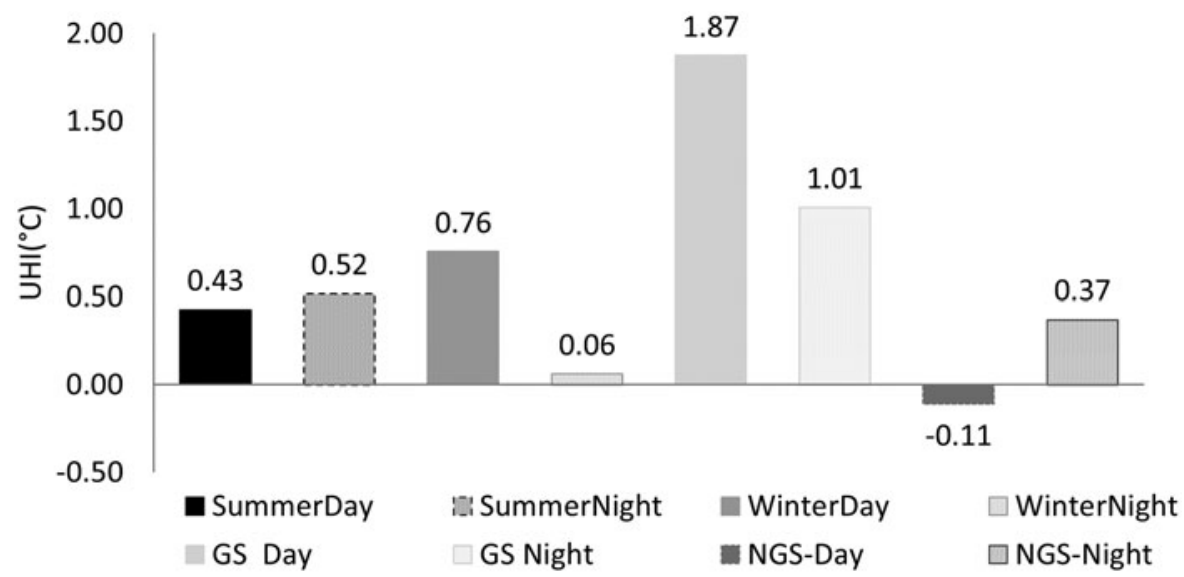

Figure 9. Seasonal averages of the UHI amplitude for daytime and nighttime.

creates a strong contrast between the temperatures in the urban core and the rural zone. The 2 indicators are in near-opposition of phase and suggest that the temperature difference between the urban and rural zone is strongly modulated by vegetation physiological activity.

Seasonal averages of UHI during day and nighttime for the urban area of Tangier are illustrated in Figure 9. Overall, the growing season UHI has the greatest amplitude during both daytime $\left(1.87^{\circ} \mathrm{C}\right)$ and nighttime $\left(1.01{ }^{\circ} \mathrm{C}\right)$. The UHI is still maintained during the non-growing season nighttime but is weak, whereas during the daytime the urban core turns into a weak UHS. During the summer and winter, the UHI is still visible both during day and night, but with much smaller amplitude (Figure 9).

\section{Urban heat island: country scale}

Since our regional results indicated that the amplitude of the UHI and UHS was more important during the
GS and NGS than during the calendar seasons, we focus the country level analysis on during these periods. We further discriminate in our country-level analysis between the average UHI and UHS by grouping all urban areas having a daytime UHI (16 urban areas) and all urban areas having a daytime UHS (3 urban areas).

We calculated the average temperature differences between the urban core and the rural zone for these groupings, for the GS daytime $(1: 30 \mathrm{pm})$ and nighttime (1:30 am).

For those urban areas which presented a positive UHI, mostly built within vegetated regions, the urban cores were on average warmer than their rural surroundings by $1.51^{\circ} \mathrm{C}$ during the daytime and $1.12^{\circ} \mathrm{C}$ at night; both of these differences are more than twice their corresponding standard deviations and therefore are unlikely to be due to chance at the $95 \%$ confidence level. On the other hand, the UHS effect occurred in those urban areas built in desert-like environments, was relatively small and does not appear to 
be statistically significant at the $95 \%$ confidence interval (Table 5). These values are within the range of those found by Zhang et al. (2010) over urban areas in the continental US.

This result suggests that, within urban areas, the urban heating may exacerbate the potential warming generated by climate change (IPCC 2014) and the global average $1.5^{\circ} \mathrm{C}$ temperature target set by the United Nations Framework Convention on Climate Change (UNFCCC 2015) may be reached sooner than expected. This implication carries a national social responsibility, knowing that more of the country's population will live in cities in the next decades.

To gain a better understanding of the spatial impact of urbanization on the surface temperature in the country, we further disaggregate the analysis for

Table 5. Country-scale average UHI (positive) and UHS (negative) amplitude and standard deviations (SD).

\begin{tabular}{lcccc}
\hline & Daytime $\left({ }^{\circ} \mathrm{C}\right)$ & SD & Nighttime $\left({ }^{\circ} \mathrm{C}\right)$ & SD \\
\hline UHI & 1.51 & \pm 0.36 & 1.12 & \pm 0.41 \\
UHS & -0.48 & \pm 0.26 & 0.30 & \pm 0.32 \\
\hline
\end{tabular}

the 12 administrative regions (Figure 10). The analysis reveals the strongest UHI over regions R1-R4, occupying the northern part of the country north of the Middle Atlas mountain, with maxima GS daytime and nighttime UHI amplitudes of $1.87^{\circ} \mathrm{C}$ and $1.48^{\circ} \mathrm{C}$, respectively, recorded in the Oriental (R1). Both during day and night the UHI decreases from the northern regions towards the interior of the country. In the semi-arid (R8) and arid (R10) regions, the daytime UHI turns into a well-defined UHS. There, trees are imported and planted in urban cores and maintained through irrigation, thus keeping the urban core cooler than its surrounding bare lands. For example, in the urban area of Guelmim the daytime UHS amplitude of $0.78^{\circ} \mathrm{C}$ is recorded with an insignificant value during nighttime when vegetation is not active.

To assess the potential relationship between the size of an urban settlement and its impact on surface temperature, we grouped the urban areas based on their size across all the selected urban areas and estimated the average daytime GS UHI and UHS. Our analysis shows that the UHI amplitude is directly proportional to the size of the urban area (Figure 11A).

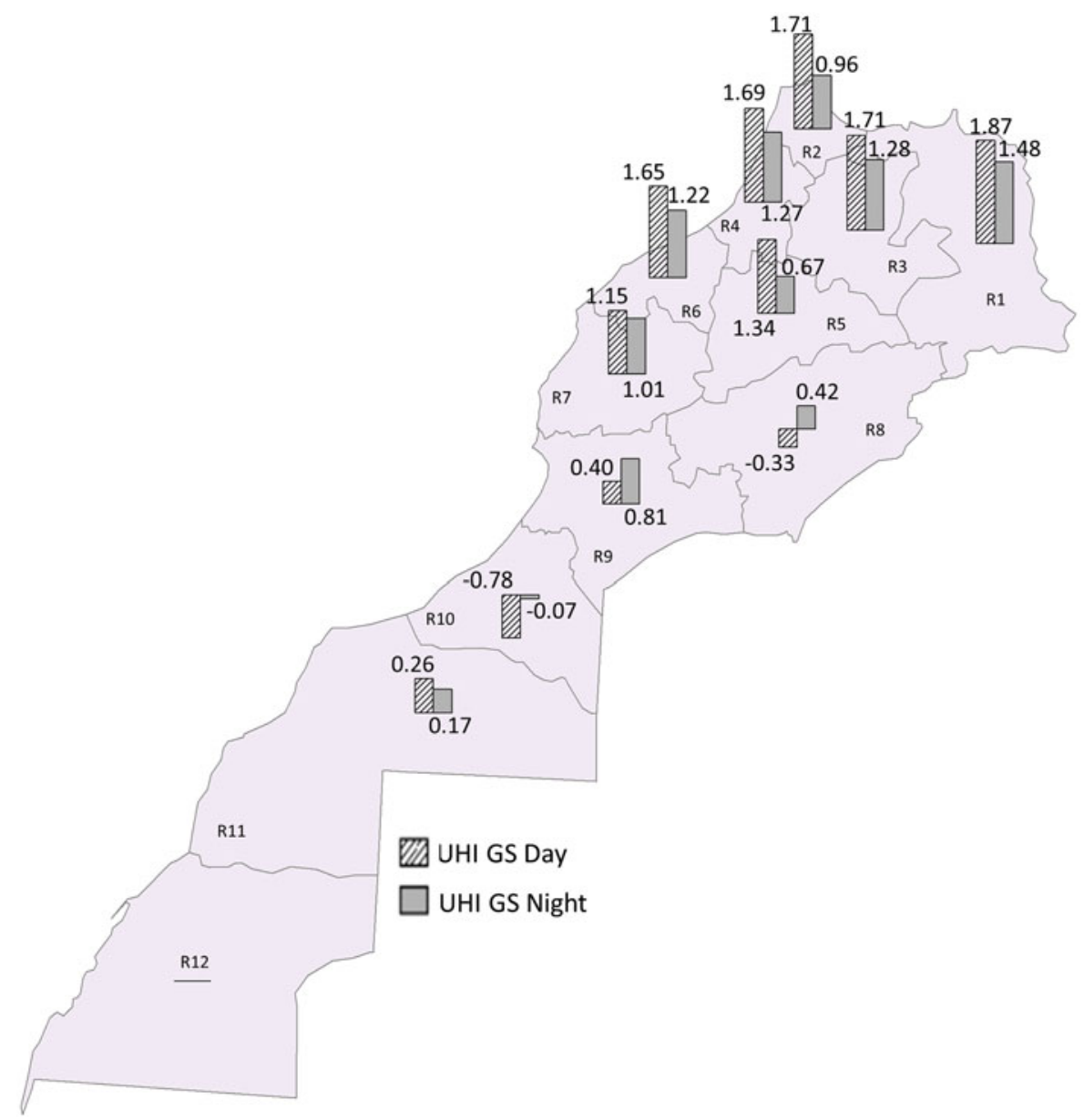

Figure 10. Regional average day and nighttime GS UHI. No LST was available for R12. 

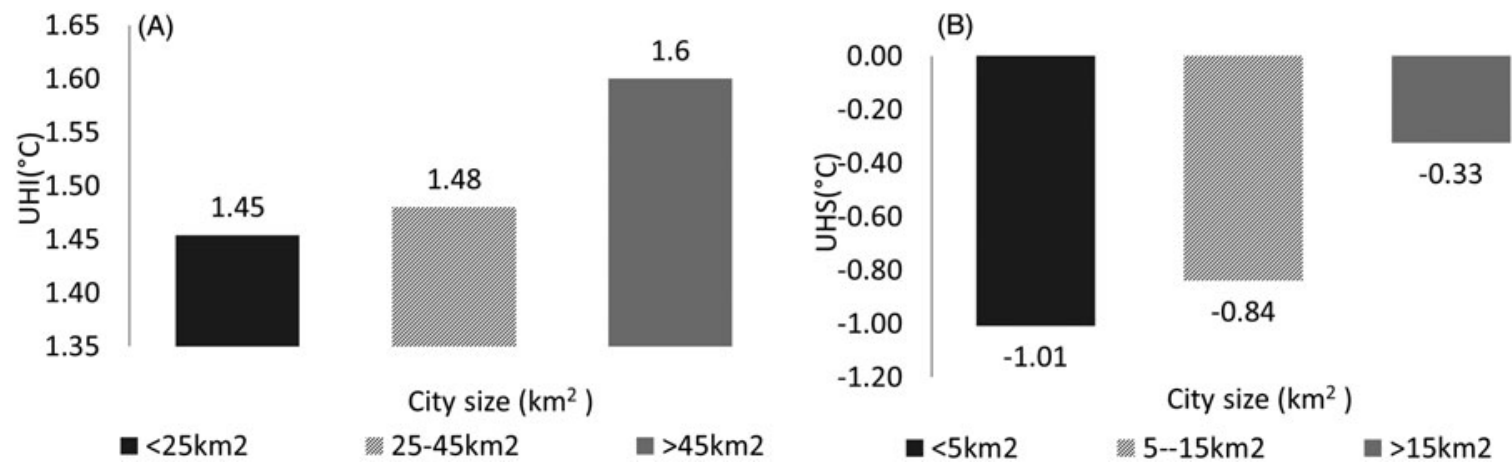

Figure 11. Average $(\mathrm{A}) \mathrm{UHI}\left({ }^{\circ} \mathrm{C}\right)$ and $(\mathrm{B}) \mathrm{UHS}\left({ }^{\circ} \mathrm{C}\right)$ of urban areas by size.

In Morocco, urban areas are not large and, as such, the average UHI amplitude is $\sim 1.5^{\circ} \mathrm{C}$. This result is in line with previous studies of UHI (e.g., Zhang et al. 2010; Imhoff et al. 2010) which showed that, for the continental US, the averaged UHI for urban areas smaller than $50 \mathrm{~km}^{2}$ is about $2.5^{\circ} \mathrm{C}$ (Zhang et al. 2010). To the contrary, we show that the UHS decreases with an increase in urban size and its amplitude is much smaller than that of the UHI. In Morocco and for the selected urban areas, the observed UHS ranges from $1.01^{\circ} \mathrm{C}$ for urban areas smaller than $5 \mathrm{~km}^{2}$ to $0.33^{\circ} \mathrm{C}$ for urban areas larger than $15 \mathrm{~km}^{2}$. This result seems counterintuitive. However, in urban areas built in desert-like environments, such as Guelmim (R10) and Ouarzazate (R8) and similar cities, the urban core is greener than its surroundings due to irrigated vegetation and, therefore, slightly cooler during the daytime. Furthermore, relatively large business districts and industrial complexes with much less vegetation often surround such urban areas, increasing thus the buildup area and reducing the UHS (Figure 11B).

In order to contextualize the urban heating and cooling effect, we construct a temperature profile across the urban core and extend it to the rural zones surrounding it. 2 urban areas, built in different ecological environments, are chosen to illustrate the cross-urban area temperature profile: the urban areas of Tetouan located in Northern Morocco (R2) and Ouarzazate located in the arid region Draa-Tafilalet (R8) in southern Morocco. While the 2 urban areas are close in terms of size, their ecological contexts, as defined by the NDVI and surface temperature, are much contrasted. Tetouan is built in a densely vegetated area with a GS mean NDVI of 0.45 , whereas Ouarzazate is built in a desert-like environment with a GS mean NDVI of 0.19. These 2 urban areas demonstrate the importance of ecological context as a modulator of the UHI effect. While the urban core in Tetouan creates a well-defined UHI with an amplitude of $1.55^{\circ} \mathrm{C}$, in Ouarzazate, the urban core is cooler than rural zones by $\sim 0.33^{\circ} \mathrm{C}$-a relatively small number compared to the accuracy of the MODIS LST product-but it nevertheless points to the direction of a heat sink, as postulated by Bounoua et al. (2009), Shepherd (2006), and Imhoff et al. (2010). The averaged GS daytime LST profile across the urban core for the 2 urban areas is shown in Figure 12.

The relationship between the UHI and the urban area size in all the selected urban areas listed in Table 2 appears quasi-linear (Figure 13) and explains $\sim 46 \%$ of the total variance with a standard error of $0.56^{\circ} \mathrm{C}$. This form of distribution is similar to the relationship between the UHI and the population size described in Landsberg (1981).

\section{Concluding remarks}

The objective of this study was to map urbanization in order to analyze the urban heat island. We focused on amplitude of the UHI and its relationship to the fraction of impervious surface, as well as the size of urban cores in urban areas across Morocco. The study uses satellite data to characterize both the urban areas, the land surface temperature, and the surrounding vegetation phenology. To date, it is the first spatial assessment of the UHI over the 24 largest urban areas characteristics of the 12 regions of Morocco.

Among the 24 selected urban areas, only 3 built in desert-like environments in southern Morocco presented an UHS. Those which presented a well-defined UHI were located in the northern part of the country and were built within a vegetated landscape. This distribution of UHI versus UHS mirrors the biogeographical distribution of the country, with large arid lands south of the Atlas Mountains and semi-arid to humid urban lands north of it. The results show the UHI to be strongly modulated by the surrounding landscape. Indeed, when an urban area is built, the choice of its building material determines its surface 


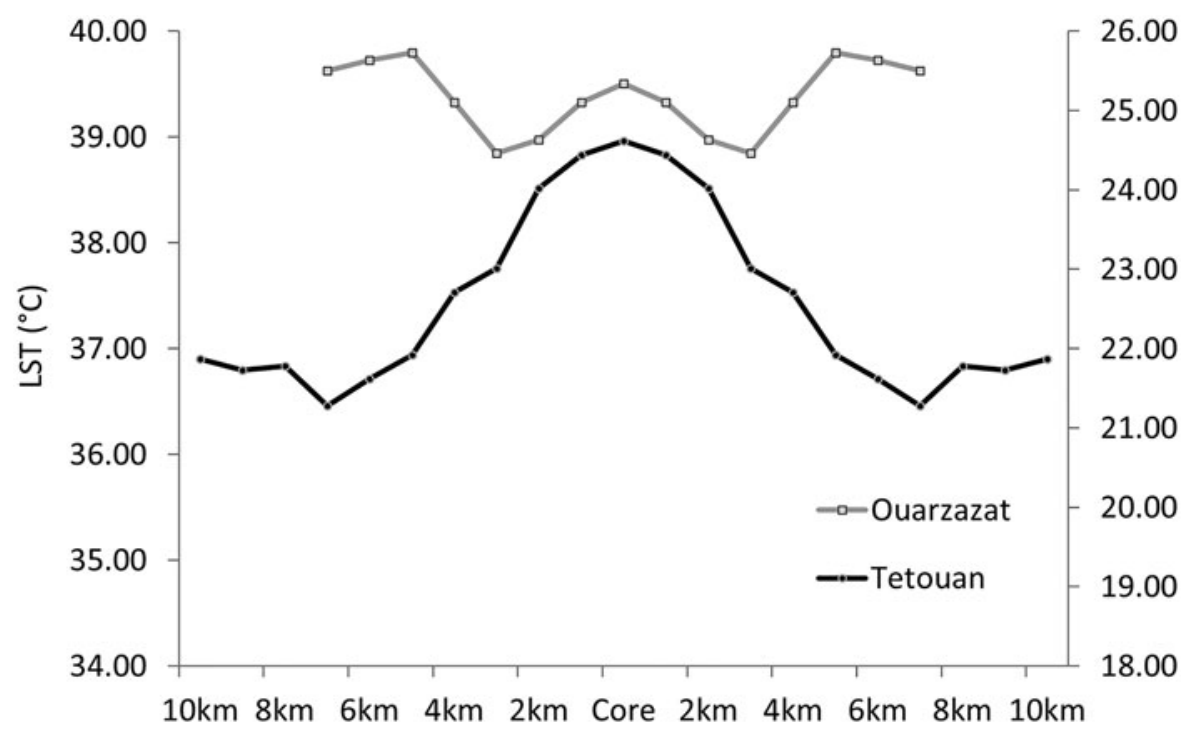

Figure 12. GS mean surface temperature profile across Tetouan and Ouarzazate. From the urban core, spatial average surface temperature is calculated using rings of pixels with outward $2 \mathrm{~km}$ increment. GS temperature $\left({ }^{\circ} \mathrm{C}\right)$ on the left-axis for Ouarzazate and on the right-axis for Tetouan.

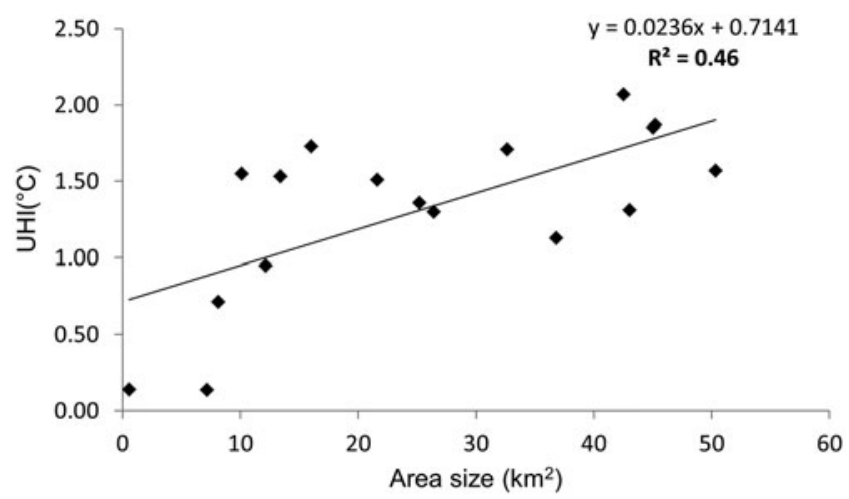

Figure 13. Relationship between UHI and urban area size in Morocco.

energy balance and, thus, its average day and nighttime temperatures. The amplitude of the UHI it forms depends greatly on the nature of its surrounding. A vegetated surrounding landscape is cooler and generates a stronger daytime UHI, whereas a non-vegetated surrounding maintains a relatively higher surface temperature, closer to that of the urban core, and, therefore, generates a much weaker UHI. In the case of an arid surrounding landscape, the urban area is often much cooler than surroundings, due to urban vegetation maintained through resource augmentation, and generates an UHS. This temperature differential is important, especially in the context of climate warming. In 2015, 196 parties to the UN Framework Convention on Climate Change (UNFCCC) adopted the Paris agreement, a legally binding framework for an internationally coordinated effort to tackle climate change. The agreement is an ambitious collective goal to hold warming well below $2{ }^{\circ} \mathrm{C}$, with efforts to limit warming to $1.5^{\circ} \mathrm{C}$. This study draws attention to urban areas, which are already warmer than their surroundings and will always be above the ambient temperature. It shows that at national level the warming brought by urbanization is $\sim 1.5^{\circ} \mathrm{C}$ during daytime and $1.12{ }^{\circ} \mathrm{C}$ at night, and this extra warming is above and beyond the climate warming referred to in the Paris agreement.

The study also reveals the important role of vegetation in modulating the urban warming and points to the use of vegetation as a natural mitigation mechanism in urban cores. From this and previous studies, it is clear that urban forests will not only help in the sequestration of more carbon from the atmosphere, but through the same process will cool the surface temperature as well.

\section{Disclosure statement}

The authors report no conflicts of interest. 


\section{Funding}

This research was partially supported by the African Climate Change Fellowship Program III (ACCFP) through funding of Najlaa Fathi's training at NASA's Goddard Space Flight Center. The ACCFP is jointly supported by Canada's International Development Research Center, the Institute of Resource Assessment at the University of Dar Es Salaam, and by START International (Global change System for Analysis, Research and Training).

\section{References}

Al-Hamdan, M.Z., Quattrochi, D.A., Bounoua, L., Lachir, A., and Zhang, P. 2016. "Using Landsat, MODIS, and a Biophysical Model to Evaluate LST in Urban Centers." Remote Sensing, Vol. 8(No. 11): pp. 952. doi:10.3390/ rs8110952.

Azmi, R., Saadane, A., and Kacimi, I. 2015. "Estimation of spatial distribution and temporal variability of land surface temperature over Casablanca and the surroundings of the city." International Journal of Innovation. App Studies, Vol. 11: pp. 49-57.

Bahi, H., Rhinane, H., Bensalmia, A., Fehrenbach, U., and Scherer, D. 2016. "Effects of Urbanization and Seasonal Cycle on the Surface Urban Heat Island Patterns in the Coastal Growing Cities: A Case Study of Casablanca, Morocco." Remote Sensing, Vol. 8(No. 10): pp. 829.

Bounoua, L., Nigro, J., Thome, K., Zhang, P., Fathi, N., and Lachir, A. 2018b. "A Method for Mapping Future Urbanization in the United States." Urban Science, Vol. 2(No. 2): pp. 40. doi:10.3390/urbansci2020040.

Bounoua, L., Nigro, J., Zhang, P., Lachir, A., and Thome, K. 2018a. "Mapping Urbanization in the United States from 2001-2011." Applied Geography, Vol. 90: pp. 123-133. doi:10.1016/j.apgeog.2017.12.002.

Bounoua, L., Safia, A., Masek, J., Peters-Lidard, C., and Imhoff, M. 2009. "Impact of Urban Growth on Surface Climate: A Case Study in Oran, Algeria." Journal of Applied Meteorology and Climatology, Vol. 48(No. 2): pp. 217-231. doi:10.1175/2008JAMC2044.1.

Bounoua, L., Zhang, P., Mostovoy, G., Thome, K., Masek, J., Imhoff, M.L., Shepherd, M., et al. 2015b. "Impact of Urbanization on US Surface Climate." Environmental Research Letters, Vol. 10(No. 8): 84010-84018. doi: 10.1088/1748-9326/10/8/084010.

Bounoua, L., Zhang, P., Nigro, J., Lachir, A., and Thome, K. 2017. "Regional Impacts of Urbanization in the United States." Canadian Journal of Remote Sensing, Vol. 43(No. 3): pp. 256-268. doi:10.1080/07038992.2017.1317208.

Bounoua, L., Zhang, P., Thome, K., Masek, J., Safia, A., Imhoff, M.L., and Wolfe, R.E. 2015a. "Mapping Biophysical Parameters for Land Surface Modeling Over the Continental US using MODIS and Landsat." Dataset Papers in Science, Vol. 2015: pp. 1. Article ID 564279. doi:10.1155/2015/564279.

Chestnut, L.G., Breffle, W.S., Smith, J.B., and Kalkstein, L.S. 1998. "Analysis of Differences in Hot Weather Related Mortality Across 44U. S. Metropolitan Areas." Environmental Science and Policy, Vol. 1(No. 1998): pp. 59-70. doi:10.1016/S1462-9011(98)00015-X.
Chow, S., Zheng, J., and Wu, L. 1994. "Solar Radiation and Surface Temperature in Shanghai City and Their Relation to Urban Heat Island Intensity." Atmospheric Environment, Vol. 28: pp. 2119-2127.

Colditz, R.R., Conrad, C., Wehrmann, T., Schmidt, M., and Dech, S. 2008. "TiSeG - A Flexible Software Tool for Time Series Generation of MODIS Data Utilizing the Quality Assessment Science Data Set.” IEEE Transactions on Geoscience and Remote Sensing, Vol. 46(No. 10): pp. 3296-3308. doi:10.1109/TGRS.2008.921412.

Dwyer, J.L., and Schmidt, G.L. 2006. The MODIS Reprojection Tool. In: Earth Science Satellite Remote Sensing. edited by Qu J.J., Gao W., Kafatos M., Murphy R.E., Salomonson V.V. Berlin, 162-177. Heidelberg: Springer.

Frey, C.M., Kuenzer, C., and Dech, S. 2012. "Quantitative Comparison of the Operational NOAA AVHRR LST Product of DLR and the MODIS LST product V005." International Journal of Remote Sensing, Vol. 33(No. 22): pp. 7165-7183. doi:10.1080/01431161.2012.699693.

Grimmond, C.S.B., and Oke, R. 2002. "Turbulent Heat Fluxes in Urban Areas: Observations and a Local-scale Urban Meteorological Parameterization Scheme (LUMPS)." Journal of Applied Meteorology, Vol. 41(No. 7): pp. 792-810. doi:10.1175/1520-0450(2002)041<07 92: THFIUA $>2.0 . \mathrm{CO} ; 2$.

HCP, Haut-Commissariat au Plan Rabat, MAROC. 2006. Statistiques Environnementales au Maroc 2006.

Huete, A.R., Justice, C., and Liu, H. 1994. "Development of Vegetation and Soil Indices for MODIS EOS.” Remote Sensing Environment, Vol. 49(No. 3): pp. 224-234. doi: 10.1016/0034-4257(94)90018-3.

Huete, A.R., Liu, H.Q., Batchily, K., and Van Leeuwen, W.J.D. 1997. "A Comparison of Vegetation Indices Over a Global Set of TM Images for EOS-MODIS." Remote Sensing Environment, Vol. 59(No. 3): pp. 440-451. doi: 10.1016/S0034-4257(96)00112-5.

Imhoff, M.L., Zhang, P., Wolfe, R.E., and Bounoua, L. 2010. "Remote Sensing of the Urban Heat Island Effect Across Biomes in the Continental USA. Remote." Sensing Environment, Vol. 114(No. 3): pp. 504-513. doi:10.1016/ j.rse.2009.10.008.

IPCC. 2014. Climate Change 2014: Synthesis Report. Contribution of Working Groups I, II and III to the Fifth Assessment Report of the Intergovernmental Panel on Climate Change [Core Writing Team, R.K. Pachauri and L.A. Meyer (eds.)]. IPCC, Geneva, Switzerland, 151. http://wedocs.unep.org/handle/20.500.11822/18928? show= full.

Kato, S., and Yamaguchi, Y. 2005. "Analysis of Urban HeatIsland Effect using ASTER and ETM + Data: Separation of Anthropogenic Heat Discharge and Natural Heat Radiation from Sensible Heat Flux." Remote Sensing Environment, Vol. 99(No. 1-2): pp. 44-54. doi:10.1016/ j.rse.2005.04.026.

Lachir, A., Bounoua, L., Zhang, P., Thome, K., and Messouli, M. 2016. "Modeling the Urban Impact on Semiarid Surface Climate: A Case Study in Marrakech, Morocco." Canadian Journal of Remote Sensing. Vol. 42(No. 4): pp. 379-395. doi:10.1080/07038992.2016. 1194746. 
Landsberg, E.H. 1981. The Urban Climate. International Geophysics Series. Vol. 28, p. 5. New York, NY: Academic Press.

Li, J., Song, C., Cao, L., Zhu, F., Meng, X., and Wu, J. 2011. "Impacts of Landscape Structure on Surface Urban Heat Islands: A Case Study of Shanghai, China." Remote Sensing Environment, Vol. 115(No. 12): pp. 3249-3263. doi:10.1016/j.rse.2011.07.008.

Library of Congress. 2006. Federal Research Division. Morocco: Country Profile.

Lillesand, T.M., Kiefer, R.W., and Chipman, J.W. 2004. Remote Sensing and Image Interpretation. Hoboken, USA: John Willey \& Sons.

Lu, D., and Weng, Q. 2006. "Spectral Mixture Analysis of ASTER Images for Examining the Relationship between Urban Thermal Features and Biophysical Descriptors in Indianapolis, Indiana, USA." Remote Sensing Environment, Vol. 104(No. 2): pp. 157-167. doi:10.1016/ j.rse.2005.11.015.

MCCP, Morocco's Climate Change Policy. 2014. "Ministry Delegate of the Minister of Energy, Mines, Water and Environment, in charge of Environment." Available at http://www.4c.ma/medias/MCCP\%20-\%20Moroccan\%20 Climate\%20Change\%20Policy.pdf.

Norjamaki, I., and Tokola, T. 2007. "Comparison of Atmospheric Correction Methods in Mapping Timber Volume with Multitemporal Landsat Images in Kainuu, Finland." Photogrammetric Engineering and Remote Sensing, Vol. 73(No. 2): pp. 155-163. doi:10.14358/ PERS.73.2.155.

Oke, T.R. 1973. "City Size and the Urban Heat Island." Atmospheric Environment Pergamon Press, Vol. 7(No. 8): pp. 769-779. doi:10.1016/0004-6981(73)90140-6.

Oke, T.R. 1982. "The Energetic Basis of the Urban Heat Island." Quarterly Journal of the Royal Meteorological Society, Vol. 108: pp. 1-24. doi:10.1256/smsqj.45501.

Owen, T.W., Carlson, T.N., and Gillies, R.R. 1998. "An Assessment of Satellite Remotely Sensed Land Cover Parameters in Quantitatively Describing the Climatic Effect of Urbanization." International Journal of Remote Sensing, Vol. 19(No. 9): pp. 1663-1681. doi:10.1080/ 014311698215171.

Quattrochi, D.A., Estes, M.G., Jr., Laymon, C.A., Crosson, W.L., Howell, B.F., Luvall, J.C., Rickman, D.L., et al. 2007. "Urban Heat Islands." In: Our Changing Planet: The View from Space, edited by M D King, 298-301. Cambridge, UK: Cambridge University Press.

RGPH. 2015. Recensement Général de la Population et de l'Habitat, Population légale des régions, provinces, préfectures, municipalités, arrondissements et communes du royaume d'après les résultats du RGPH 2014 (12 Régions).

Roy, D.P., Borak, J.S., Devadiga, S., Wolfe, R.E., Zheng, M., and Descloitres, J. 2002. "The MODIS Land Product Quality Assessment Approach." Remote Sensing Environment, Vol. 83(No. 1-2): pp. 62-76. doi:10.1016/ S0034-4257(02)00087-1.

Shepherd, J.M. 2006. "Evidence of Urban-Induced Precipitation Variability in Arid Climate Regimes." Journal of Arid Environments, Vol. 67(No. 4): pp. 607-628. doi:10.1016/j.jaridenv.2006.03.022.
Shepherd, J.M., and Burian, S.J. 2003. "Detection of Urbaninduced Rainfall Anomalies in Major Coastal City." Earth Interactions, Vol. 7(No. 4): pp. 1-17. doi:10.1175/10873562(2003)007<0001:DOUIRA > 2.0.CO;2.

Souch, C., and Grimmond, S. 2006. "Applied Climatology: Urban Climate." Progress in Physical Geography, Vol. 30(No. 2): pp. 270-279. doi:10.1191/0309133306pp484pr.

Streutker, D.R. 2002. "A Remote Sensing Study of the Urban Heat Island of Houston, Texas." International Journal of Remote Sensing, Vol. 23(No. 13): pp. 2595-2608. doi:10.1080/01431160110115023.

UN. 2014. United Nations, Department of Economic and Social Affairs, Population Division. World Urbanization Prospects: The 2014 Revision.

United Nations/Framework Convention on Climate Change (UNFCCC). 2015. Adoption of the Paris Agreement, 21st Conference of the Parties, Paris: United Nations. Available at unfcc.int/resource/docs/2015/cop21/eng/109r01.pdf

UN-HABITAT. 2016. World Cities Report 2016: Urbanization and development. Emerging futures.

Wang, W., Liang, S., and Meyers, T. 2008. "Validating MODIS Land Surface Temperature Products using Longterm Nighttime Ground Measurements." Remote Sensing Environment, Vol. 112(No. 3): pp. 623-635. doi:10.1016/ j.rse.2007.05.024.

Weng, Q. 2009. “Thermal Infrared Remote Sensing for Urban Climate and Environmental Studies: Methods, Applications, and Trends." ISPRS Journal of Photogrammetry and Remote Sensing, Vol. 64(No. 4): pp. 335-344. doi:10.1016/j.isprsjprs.2009.03.007.

Yuan, F., and Bauer, M.E. 2006. "Mapping Impervious Surface Area using High Resolution Imagery: A Comparison of Object-based and Per Pixel Classification." In American Society for Photogrammetry and Remote Sensing - Annual Conference of the American Society for Photogrammetry and Remote Sensing 2006: Prospecting for Geospatial Information Integration, Vol. 3: pp. 667-1674.

Zhang, J.H., Hou, Y.Y., Li, G.C., Yan, H., Yang, L.M., and Yao, F.M. 2005. "The Diurnal and Seasonal Characteristics of Urban Heat Island Variation in Beijing City and Surrounding Areas and Impact Factors Based on Remote Sensing Satellite Data." Science China, Vol. 48D: pp. 220-229.

Zhang, P., Bounoua, L., Imhoff, M.L., Wolfe, R.E., and Thome, K.J. 2014. "Comparison of MODIS Land Surface Temperature and Air Temperature Over the Continental USA Meteorological Stations." Canadian Journal of Remote Sensing, Vol. 40(No. 2): pp. 110-122.

Zhang, P., Imhoff, M.L., Bounoua, L., and Wolfe, R.E. 2012. "Exploring the Influence of Impervious Surface Density and Shape on Urban Heat Islands in the Northeast United States using MODIS and Landsat." Canadian Journal of Remote Sensing, Vol. 38: pp. 441-451.

Zhang, P., Imhoff, M.L., Wolfe, R.E., and Bounoua, L. 2010. "Characterizing Urban Heat Islands of Global Settlements using MODIS and Nighttime Lights Products." Canadian Journal of Remote Sensing, Vol. 36(No. 3): pp. 185-196. doi: $10.5589 / \mathrm{m} 10-039$.

Zhao, L., Lee, X., Smith, R.B., and Oleson, K. 2014. "Strong Contributions of Local Background Climate to Urban Heat Islands.” Nature, Vol. 511(No. 7508): pp. 216-219. doi:10.1038/nature13462. 